\title{
El infierno de la clase obrera argentina. Desde un pasado venturoso a un presente sin porvenir
}

\author{
Battistini, Osvaldo R.* \\ * Investigador adjunto del CONICET. Coordinador del área "Identidades y \\ representaciones" del CEI L-PIETTE. Profesor de la Universidad de Buenos Aires. Dirección \\ postal: CEIL-PIETTE, Saavedra 15, $4^{\circ}$ piso, C1083ACA Ciudad de Buenos Aires. E-mail: \\ battisti@mail.retina.ar , obattistini@ceil-piette.gov.ar
}

\section{Resumen}

La conjunción de una serie de factores económicos, sociales y políticos en la Argentina de los noventa dio como resultado el momento de mayor fragmentación política de los trabajadores. Esto fue logrado a partir de la desestructuración de la sociedad comenzada en la dictadura militar de mediados de los setenta y profundizada mediante la implantación del modelo neoliberal a comienzos de la última década del siglo XX. Se terminó entonces dilapidando toda posibilidad de consolidación de la una clase obrera mas o menos homogénea, cuyo germen había sido prefigurado bajo el primer gobierno peronista y se había puesto de manifiesto en las distintas etapas de la resistencia a gobiernos que amenazaban los intereses de los sectores populares. Sin dudas se trataba de políticas destinadas a asegurar una sociedad disciplinada con el fin de consolidar el poder de los sectores dominantes más relacionados con la especulación financiera y los intereses de los grupos económicos transnacionales. Al mismo tiempo, no sólo se lograba una sociedad económica y socialmente fragmentada sino que se reproducía una cultura individualista extrema que potenciaba dicha situación. En el presente artículo estudiamos los elementos condicionantes en la cultura del trabajo que existían en la historia previa a la implantación del modelo neoliberal y los factores contextuales que permitieron su desarrollo. Al mismo tiempo analizamos los factores que, en un marco de fragmentación y transformación constante, estructuran actualmente las identidades del trabajo.

Palabras clave: Identidad, trabajo, clase obrera. 


\title{
The Hell of the Argentinian Working Class: From a Promising Past to a Present Without Future
}

\begin{abstract}
The convergence of a series of economic, social and political factors in Argentina in the 1990s resulted in the greatest fragmentation of labor policy in that country. This occurred due to the de-structuring of the society that began in the military dictatorship beginning in the 1970s, a process which worsened with the imposition of the neo-liberal economic model implanted at the beginning of the last decade of the XXth Century. All of this resulted in the dilapidation of the possibility of consolidating a more or less homogeneous labor class, the germ of which had been pre-configured in the first Peronist government, and which had been manifested during different stages of the resistance to governments that threatened the interests of the popular sectors. Without doubt these policies were destined to insure a disciplined society for the purpose of consolidating power in the dominant sectors more related with finance and the interests of transnational economic groups. At the same time, not only was an economic and socially fragmented society achieved, but a culture of extreme individualism was empowered by this situation. This article studies the conditioning elements in the work culture that historically existed in the history of the country prior to the implantation of the neo-liberal model, and the contextual factors that permitted its development. At the same time we analyze the factors that, within the framework of constant fragmentation and transformation, presently structure the work identity.
\end{abstract}

Key words: Identity, work, working class.

Recibido: 03-11-17. Aceptado: 04-03-31

“Si arrastré por este mundo la vergüenza de haber sido y el dolor de ya no ser, bajo el ala del sombrero cuantas veces embozada una lágrima asomada yo no pude contener." Primer fragmento del tango de Carlos Gardel y Alfredo Le Pera: Cuesta Abajo

\section{I ntroducción}

Si en los años en los cuales la realidad social, económica y política argentina se asemejaba a ciertas características de los Estados de Bienestar europeos y las relaciones laborales adquirían similitudes al fordismo preponderante en las economías centrales, la 
clase obrera se constituía por un lado en el elemento dinamizador del régimen de acumulación y de la forma de producción, y por el otro en el sujeto capaz de encarnar la transformación del sistema, en la actualidad puede decirse que de esa misma clase, como elemento monolítico y propulsor de valores, quedan solo rastros.

A favor de la implementación de parámetros de corte neoliberal en la economía y de técnicas del management dirigidas a establecer un mejor control de la producción y de la subjetividad de los trabajadores, se produjo una fuerte fragmentación de estos últimos y la transformación de sus propias perspectivas sobre la realidad presente y sobre el futuro.

Las nuevas culturas del éxito rápido, de los valores modernos, del triunfo de los jóvenes, se impusieron sobre la idea de carreras y ascensos sociales paulatinos dirigidos a la obtención de credenciales de formación y un futuro a través del trabajo estable. Las estructuras productivas fueron modificándose, introduciendo nuevas formas organizacionales y tecnologías que las hicieron menos dependientes de la incorporación de los trabajadores en masa. La desocupación y la precarización se hicieron, entonces, la norma y no la excepción. Casi como parte del mismo proceso, los movimientos políticos ligados a los sectores populares y las organizaciones reivindicativas de los trabajadores perdieron la fuerza y el espacio que ocupaban en la representación del conjunto de los mismos. Este triple movimiento generó las condiciones para que ya no podamos hablar de homogeneidades en las construcciones identitarias que se producen en el mundo del trabajo. La multiplicidad de situaciones y la preponderancia de las incertidumbres da como resultado la proliferación de lugares y valores, que son ocupados mas o menos caóticamente por trabajadores distintos en distintos momentos de su propia historia como tales. Esta poliformidad de los trabajos y su inconstancia en el tiempo dificulta las pertenencias y, desde allí, la puesta en marcha de proyecciones a futuro y el desarrollo de acciones políticas cercanas a los sectores populares.

En el artículo que presentamos estudiamos los elementos que caracterizaban la cultura del trabajo en Argentina hasta los años setenta y cuales son los que lo caracterizan en la situación actual. A partir de esto, analizamos que factores estructuran actualmente, en un marco de fragmentación y transformación constante, las identidades en el trabajo.

En un primer apartado presentamos los aspectos que distinguieron la construcción de la clase obrera argentina en función de los parámetros generados en el transcurso de la implantación y desarrollo del modelo de estado interventor y la cristalización de una sociedad donde primaba la relación salarial clásica del fordismo. Luego analizamos las transformaciones de la identidad y las referencias al trabajo $\underline{1}$, contrastando entre aquellas 
que derivaron de la relaciones establecidas por el trabajador con el peronismo y el sindicalismo. En el tercer apartado describimos los actuales condicionantes a la construcción de relativas homogeneidades en las identidades de los trabajadores en Argentina.

\section{Particularismos de la clase obrera en Argentina}

La construcción de relaciones sociales estables asentadas sobre un horizonte de vida seguro, certero y calculable era el basamento sobre el cual se apoyaba la estructura del Estado bienestarista vigente desde fines de la segunda guerra mundial hasta mediados de los setenta. Dentro de esa lógica de funcionamiento societal, el ser un trabajador con una relación salarial formal era garantía suficiente para alcanzar la propia existencia social. En ese mismo sentido, es importante tener en cuenta que, aún hoy, cuando esta realidad no es la preponderante, el asalariado es juzgado/ubicado por su situación de empleo, y el conjunto de estos trabajadores encuentran, a partir de esta forma de inclusión, su común denominador y existen socialmente desde ese lugar (Castel, 1995).

La empresa capitalista característica del modelo bienestarista reproducía una cultura laboral que reforzaba la identificación de los trabajadores entre sí, que asentaba la construcción de un "nosotros" del grupo obrero, enfrentado a un "ellos" de los otros, de quienes no participaban de esa cultura, a quienes se rechazaba violentamente o hasta a algunos de ellos se los ridiculizaba (los obsecuentes, los jefes, los supervisores) (Beaud y Pialoux, 1999).

El saber obrero, la capacidad del trabajo manual era valorada mas que cualquier otro conocimiento dentro de la fábrica. Sólo quien estaba en contacto directo con la producción era el que tenía el conocimiento verdadero, que a su vez le permitía contar con un espacio estable en la producción (el puesto de trabajo). Para ocupar un lugar en el grupo de obreros había que "saber hacer" con las manos, tener facilidad para manejar las máquinas. La tecnología era aprensible por los trabajadores, pero el acceso a ellas se realizaba en función de los aprendizajes en ese lugar del trabajo. Además el saber era transmitido por los viejos trabajadores a los mas jóvenes, lo cual implicaba además una transmisión importante de valores del trabajo y de la relación con los otros (compañeros, superiores, técnicos, representantes sindicales).

Particularmente en nuestro país, las características de la tecnología, como producto de la inserción importada de diferentes capitales y el traslado de maquinarias ya amortizadas en el país de origen, requería de la adaptación permanente de las mismas a las 
necesidades de la producción. Eran los mismos trabajadores los que realizaban estas adaptaciones y quienes, por lo tanto, pasaban a tener un importante grado de control sobre las mismas. La transmisión de saberes productivos era acompañada por un valor agregado cultural de mucho valor substancial, tanto para el trabajador como para el mismo empresario, ya que en muchos casos, las transformaciones realizadas a la máquina por los mismos trabajadores no habían sido trasladadas a planos o manuales técnicos, eran solo conservadas en la memoria cultural obrera y solo transmitida por los códigos relacionales establecidos entre los mismos compañeros de trabajo. Además, y quizás como consecuencia de esta lógica de funcionamiento productivo, aunque las estratificaciones obreras estaban institucionalizadas (vía convenios colectivos o normas internas de la fábrica) eran los mismos trabajadores quienes, en cierta medida, controlaban su desarrollo. En este caso, la representación sindical en la fábrica cumplía las veces de reaseguro o garantía a las movilidades ascendentes de los obreros, otorgando poder para relativizar el avance del capital sobre ellos y sus derechos.

Bajo el desarrollo de una sociedad de pleno empleo, el grupo obrero podía pensarse aun en términos de clase: con sus propios representantes en la fábrica -quienes eran tenidos como personajes respetados dentro de ella-, él ofrecía un marco de identificación y de socialización para todos quienes ingresaban en el mismo. Por otra parte, la multiplicidad de desafíos que eran enfrentados con éxito como colectivo hacía que se consolide su propia identidad de grupo (Beaud y Pialoux, 1999).

Las acciones llevadas a cabo por las representaciones político-sindicales reforzaban la identidad de clase. El vínculo político con el sindicato era el reaseguro de las conquistas dentro del territorio del capital. Dicha organización constituía el espacio privilegiado de correlación entre lo individual y lo colectivo. El sindicato ocupaba el espacio desde donde, sus miembros, articulaban el conflicto y la negociación. De esta forma los trabajadores quedaban relevados del enfrentamiento individual con el capital, que los hubiera colocado en una relación de absoluta desigualdad.

Por su parte, el Estado era el encargado de minimizar los riesgos que podían derivar en situaciones de indefensión de los individuos. Los mecanismos dirigidos a expandir los derechos sociales constituían un acceso particular a la propiedad. Se trata de lo que este

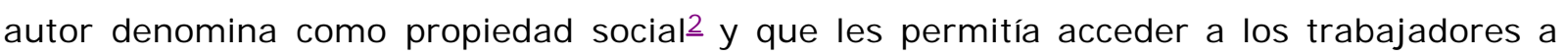
una condición de individuos en sentido positivo (Castel y Haroche, 2001).

La propiedad social representa una nueva condición, un recurso históricamente inédito para asegurar el acceso a la independencia y a la propiedad de sí. Se supera así la aporía 
en la cual estaba metida la propiedad privada, de ser a la vez necesaria e imposible de generalizar. Según R. Castel y Haroche (2001) "la sociedad salarial se constituía en una sociedad de parecidos (un continuum de posiciones), pero de parecidos-diferentes (continuum diferenciado)".

En este contexto, la fábrica aparecía como el lugar del reconocimiento social. El hecho de alcanzar un espacio en la producción representaba la seguridad de poder ocupar lugares privilegiados en otros espacios. El trabajador sentía su completitud a partir de ganarse el sustento diario, el de su familia y tener, a partir de ese ingreso salarial, la libertar de elegir tiempos de disfrute y acceder a formas de consumo que lo separaban por un tiempo diario del sacrificio desgastante de la fábrica. Aunque esto último sucedía, el malestar en la jornada diaria de empleo se canjeaba por el bienestar, del consumo garantizado y progresivo, fuera de ella. Además, ese lugar en la empresa era al cual se volvía día a día, sin pensar que existía la posibilidad de que en algún momento esto no se hiciera posible. Un elemento fundamental que permeaba las relaciones sociales era que la condición de trabajador garantizaba la seguridad futura para él y para su prole.

El tiempo diario pasado en la fábrica estaba fijado de antemano y posibilitaba el manejo del tiempo propio fuera de la fábrica. El tiempo de trabajo pautaba el resto del tiempo libre, pero habilitaba, a través de un ingreso monetario suficiente, el acceso a otros lugares (esparcimiento, vacaciones, entre otros). Las vacaciones constituían la posibilidad de obtener un tiempo propio, disfrutado con una lógica distinta al del tiempo libre de cada jornada diaria de trabajo. En este caso, se trataba de una época en el año en la cual los trabajadores asalariados tenían la posibilidad de gozar de un descanso, que los acercaba, en cierta forma a la clase burguesa 3 . De cualquier modo, las características de dicho disfrute no eran iguales para las distintas clases sociales. En Argentina, la posibilidad de contar con un tiempo de vacaciones no implicó, inmediatamente, que los trabajadores hicieran del mismo una oportunidad para dedicarlo al turismo. Esta alternativa fue solo posible en el momento en que el ingreso comenzó a ser suficiente para ello, o cuando las otras necesidades estaban cubiertas (vivienda, educación para los hijos, infraestructura del hogar, entre otros). De cualquier modo, la existencia de servicios turísticos pertenecientes a las propias organizaciones sindicales constituyó un elemento que facilitó esa posibilidad. Al mismo tiempo, cuando los trabajadores salieron masivamente de vacaciones a distintas zonas turísticas del país, le imprimieron a estos ámbitos características particulares, lo cual implicó el desplazamiento de las clases altas y medias altas a otros territorios. Esto significaba que la clase obrera hacía uso de este derecho pero llevando consigo sus particularismos, que contrastaban con los de los sectores sociales que tradicionalmente se desplazaban hacia los lugares de veraneo. 
Por otra parte, el desarrollo de las obras sociales sindicales fue un elemento de importancia en la constitución del particularismo obrero en Argentina. La expansión de la clase obrera y el consiguiente aumento de los ingresos monetarios 4 que recibían estas organizaciones hizo que los servicios de salud y aún el de turismo $\underline{5}$ crecieran exponencialmente en poco tiempo. Así, las prestaciones que se alcanzaron no tenían mucho que envidiarles a las del sector privado, lo cual, por un lado, representaba una importante cantidad de ingresos que no derivaban a este último sector $y$, por otro lado daban lugar a formas de ampliar la ciudadanía obrera hasta perforar los espacios tradicionales de las clases sociales económica y estatutariamente mas acomodadas.

En base a lo dicho en los párrafos anteriores, podemos afirmar que, en Argentina la propiedad social, otorgada por el Estado, era complementada, en forma sustancial, por los sindicatos, mediante los instrumentos sociales a su cargo.

Es importante destacar, por otro lado, que la fábrica no solo implicaba un lugar destinado a la obtención de un ingreso. Ese espacio era el alimento corriente y fundamental de todas las sociabilidades.

En este último sentido, el hecho de estar en una relación salarial por tiempo indeterminado generaba la posibilidad de acceder, entre otras cosas, a una vivienda. A partir de esto se obtenía un lugar en un barrio determinado, en el cual se reproducían relaciones de proximidad con los vecinos. La expansión de los barrios obreros y su desarrollo fueron durante muchos años el símbolo del progreso, sobre todo en las sociedades más atrasadas. La extensión de la urbanización iba de la mano del crecimiento industrial y el aumento del empleo asalariado.

La educación, por su parte, también ocupaba un lugar esencial en la constitución de valores relacionados con la inserción en el espacio laboral y, por este medio, el desarrollo de la posibilidad de obtener los bienes necesarios para acceder al progreso individual y colectivo. La educación era la vía de entrada a un trabajo y a su vez el trabajo era el reaseguro para que, por su intermedio, se expandan las posibilidades de obtención de credenciales de formación. Esto último se daba sobre todo en el plano familiar, ya que un signo de progreso a nivel del trabajo eran los títulos universitarios que podían obtener los hijos de los trabajadores. En nuestro país, la cultura de "mi hijo el doctor" había calado hondo en el ideario de los sectores obreros, que encontraban en el ascenso social familiar una forma de ascenso propio y, en el fondo, una forma de hacer perdurar, mas allá de su vida activa, el bienestar conseguido tras largos períodos de sufrimiento $\underline{6}$. No podían salir 
ellos mismos de su situación de trabajo asalariado y el sometimiento que esto significaba, pero si podían garantizar que sus hijos, a través del estudio, no tengan que recorrer el mismo camino para llegar a posiciones mas elevadas en la estructura social. A pesar de la satisfacción que implicaba contar con un empleo seguro, en cierta forma podía hablarse de cierta resistencia a que ese mismo lugar sea ocupado por sus hijos. Este elemento pudo haber constituido un factor que fue minando las posibilidades de constitución de una clase obrera con una visión relativamente homogénea de su posición en la relación con el capital, así como de sus posibles perspectivas de progreso a partir de la organización y la lucha.

El ingreso monetario, producto del empleo asalariado, garantizaba la estabilidad familiar y aseguraba el futuro. La propiedad que se obtenía no era solo material sino simbólica, dado que los diplomas implicaban una forma de valorización futura mucho mayor que la que el dinero corriente podía generar en forma inmediata.

A partir de estas afirmaciones, podemos aventurar que quizás la cultura obrera nunca estuvo firmemente enraizada en los trabajadores de nuestro país. Por diversas razones siempre plantearon formas de salida de esa relación, que se manifestaron de diversas maneras: bajo la idea de constituirse en un trabajador por cuenta propia, de irse algún día del país a probar suerte en actividades mas lucrativas, de "volver" a la tierra propia o de sus padres.

Como ya dijimos, en definitiva, la fábrica otorgaba un "lugar", un espacio de pertenencia, que desde el trabajo se transformaba en reconocimiento social, en espacio social de referencia frente a los otros.

La cultura obrera, reproducida en la fábrica, como ámbito privilegiado, impregnaba además distintos espacios de la relación social. El ingreso a un empleo asalariado como obrero significaba el paso por una serie de aprendizajes, que no eran solamente el de las tareas que constituían el puesto de trabajo, sino que eran también el conjunto de valores y datos de sociabilidad que se esforzaban para reproducir los viejos trabajadores. La necesidad de que los nuevos trabajadores incorporen hábitos y códigos de grupo era una forma de garantizar, también, ciertos núcleos de resistencia al capital. Si el taylorismofordismo se asentaba en estrictas normas de racionalización y control, los trabajadores encontraban en sus códigos relacionales el resguardo para evitar que el cumplimiento estricto de dichas normas redunde en el sobre-esfuerzo y el agotamiento diario.

La organización de la producción se articulaba con la de las relaciones contractuales. Los 
intereses del capital y el trabajo se entrecruzaban en función de normas productivas y de distribución de beneficios. La contradicción que se expresaba en el momento de la producción quedaba velada en el momento del consumo.

De cualquier modo, una organización de la producción de tipo vertical, profundamente jerarquizada y con controles cercanos muy fuertes, cuyo objetivo era alcanzar un alto grado de disciplina al interior de la fábrica, tenía su contrapartida en la multiplicación de parecidos entre los trabajadores. La estructuración de un trabajo por puestos, con diferenciaciones entre las tareas, pero asentándose en la proximidad de las calificaciones igualaba mas que diferenciaba.

Por otra parte, esa misma estructura cuasi-horizontal entre los obreros, que para la empresa funcionaba como correa de transmisión de saberes profesionales, para los trabajadores era la vía fundamental para transmitir culturas políticas y formas de resistencia. La imbricación entre las modalidades y formas de la actividad sindical con las

prácticas laborales y el desarrollo de los grupos de "compañeros" alrededor de los distintos puestos de trabajo generaron las condiciones de transmisión para determinada cultura en el entramado de relaciones laborales -también conformadas como relaciones sociales entre personas "constituidas" por una historia común- (Beaud y Piauloux, 1999).

\section{Entre el peronismo y la debacle}

Hasta principios de los setenta, en Argentina, las estructuras del peronismo y del sindicalismo actuaban como núcleos desde donde los trabajadores construían sus identificaciones. En sus orígenes, el peronismo actuó como una fuerza disruptiva que definió nuevos clivajes políticos, que puso en un plano de relativa igualdad a los trabajadores entre sí y respecto a gran parte de los sectores dominantes (Svampa, 2000), que generó, bajo la misma lógica la inserción ciudadana de la clase obrera y que, a partir de estos elementos, dio espacio para la configuración de nuevas formas identitarias 7 . A partir de ellas se posicionaban en sus relaciones con el capital. La inserción en colectivos políticos fuertes, con capacidad institucional para enfrentar a los poderes del capital en si mismo y a los constituidos en el Estado, dotaba de potencia a la identidad de los trabajadores.

La identidad reforzada por las potencialidades de las organizaciones populares se articulaba a partir de árculos concéntricos de inclusión, uno de ellos el de la política partidaria y la apelación mas cercana al Estado (encarnado por el peronismo) y el otro, mas próximo al espacio laboral, y relacionado con las demandas generadas a partir de ese 
lugar (el sindicato). Los dos espacios estaban interrelacionados desde líneas ideológicas comunes. En una primera época el primer círculo de inclusión (el peronismo) era el mas general o amplio, y desde allí se generaba el acceso al círculo mas cercano al trabajo (el sindicato) $\underline{8}$. Con el tiempo, y ante los distintos procesos que dificultaron la acción directa del círculo político partidario, el sindicato ocupó un lugar de preponderancia 9 y pasó a ser, para los trabajadores (sobre todo en el caso de los más jóvenes), el espacio privilegiado de integración. Por otra parte, la provisión y expansión de los servicios dirigidos a los trabajadores por parte de las estructuras obreras, hizo que a partir de los años sesenta, las mismas generaran una atracción per se, gracias a la posibilidad de ofrecer recursos de propiedad social. En todo este proceso, lo político actuaba como articulador de distintas dimensiones del trabajador, de su propia historia y del momento en que estaban insertos, lo cual da cuenta de que lo que se configura es una situación donde las identidades individuales se incorporan a una identidad colectiva. Pero además, podemos decir que dicha incorporación superó a la misma historia del primer peronismo en el poder, debido a que las mismas actuaban como nutrientes de una relación que se resignificaba en forma permanente. Los jóvenes que llegaban, tras la memoria de sus padres, al partido o al sindicato, no sólo traían el recuerdo de lo que "había sido" sino también la posibilidad de aportar a un espacio de lucha para que se reconozca y conserve aquello que se había conquistado (ya sea en forma de ley, en beneficios que otorgaba el Estado o en prerrogativas en la misma unidad de producción). El espíritu que amalgamaba a los nuevos y a los viejos militantes giraba en torno al momento de la "resistencia" a los poderes constituidos, para abonar el camino que permitiera una "vuelta" en el futuro.

En este contexto y bajo los parámetros relacionales señalados se consolidaban identificaciones y pertenencias fuertes, desde lo colectivo a lo individual y viceversa, que se ponían de manifiesto en la relación con los “otros" opuestos (la fábrica y el patrón).

El peronismo y el sindicalismo permeaban fuertemente la identidad de los trabajadores. Se establecían relaciones más refractarias que reflejas respecto a estas dos instituciones, produciéndose una adaptación consensuada de los valores ideológicamente dominantes en cada una de ellas. En el proceso de construcción identitaria de los trabajadores, la aparición del peronismo constituyó un elemento de fundamental importancia. Las transacciones identitarias realizadas por los individuos que ingresaban al partido o al sindicato implicaban mayor aceptación e incorporación a la identidad que traían desde su historia de vida que rechazo de los valores generados en ese espacio institucional $\underline{10}$. Este afuera "hospitalario" para el trabajador hacía que en la relación de trabajo, el obrero tuviera la suficiente potencia para rechazar mas de lo que incorporaba. En ese mismo sentido las relaciones con la empresa eran mas reflejas que refractarias. 
El peronismo actuaba como dador de sentido, lugar de pertenencia individual y generador de poder, que se ponía de manifiesto en los espacios donde se articulaba la relación con el capital.

Por otra parte, tal como lo explicamos en el apartado anterior, en términos de Castel (1995), dicha existencia individual era positivamente conformada por la presencia de un Estado que, bajo el signo del populismo, garantizaba el acceso a la propiedad social de todos los trabajadores.

¿Qué pasa hoy cuando tanto el peronismo como el sindicalismo no pueden jugar el mismo papel que el que jugaron desde mediados de los cuarenta hasta principios de los setenta?

Tratando de responder a esta pregunta, podemos considerar que en la actualidad, en algunos casos los términos se invierten, con un adentro laboral que se vuelve mucho más refractario que el afuera político. Las organizaciones que amparaban a los trabajadores ya no cuentan con estructuras que otorgan el mismo poder de sus épocas de auge. Los anclajes simbólicos y materiales que establecían los vínculos individuales con ellas se han roto. Pero además, esta ausencia se suma a la inhospitalidad de un "afuera" donde la amenaza comienza con la desocupación y termina con la exclusión social. En el espacio laboral quedan los trabajadores aislados, sin un "nosotros" que los contenga y que les otorgue protección. Esta situación hace que se diluyan las semejanzas entre ellos y las diferencias respectos al otro ajeno (el patrón). Este último aprovecha esta coyuntura y logra producir y reproducir situaciones de identificación de los trabajadores con el núcleo productivo propio.

En un principio, para los trabajadores con empleo asalariado y contratos relativamente estables $\underline{11}$, estas identificaciones pueden ser de dos tipos: forzadas o por consenso. En el primer caso nos estamos refiriendo a las situaciones en las cuales, a pesar de que los trabajadores cuenten con contratos por tiempo indeterminado, sobre ellos se generan permanentes presiones que tienden a tensionar las relaciones internas con sus compañeros y con el mismo trabajo. Se trata de las situaciones en las cuales el modelo de relaciones laborales tiende a generar competencias por los lugares, entre los mismos trabajadores y con el espacio exterior. En ese sentido, la pertenencia al grupo y al mismo espacio laboral tiende a ser débil, y la identificación con el trabajo coyuntural y forzada por las circunstancias. En el segundo caso, lo que la empresa ofrece como transacción comienza por la seguridad en el puesto y la posibilidad de ascender en él, sin que se trate 
necesariamente de una competencia encarnizada con los compañeros. A partir de esto, se generan una serie de transacciones simbólicas ligadas al prestigio del lugar ganado y la proyección a lugares de mayor jerarquía en la misma empresa.

En ambas formas identitarias prima la posibilidad de "dar" u "otorgar" que tiene la empresa, hoy desmedidamente mucho mayor que la que tienen las organizaciones que antes nucleaban a los trabajadores. La empresa pone a disposición de los trabajadores una multiplicidad de recursos, pero su otorgamiento está absolutamente condicionado $\underline{12}$. El principal de esos recursos es el empleo que, ante su ausencia masiva en el mercado, es administrado discrecionalmente, actuando de esa forma como elemento disciplinador por antonomasia. Ligado al empleo puede estar la posibilidad de contar con un salario relativamente elevado, que al combinarse con expectativas de ascenso rápido y cercanía a los nuevos sectores seudopoderosos puede constituirse en la puerta de acceso a otros recursos materiales o simbólicos. El primero de estos últimos es la posibilidad de contar con una gran capacidad de ahorro individual, acceder a beneficios sociales destinados a las capas altas y medias de la población y tener a disposición el dinero suficiente para responder a pautas de consumo suntuario. El neoliberalismo hizo que este patrón de conducta se conformara en un parámetro cultural de importancia, sobre todo para ciertas fracciones de la población. El comportamiento moderno de la sociedad era asimilado a la posibilidad de acceso a un consumo similar al del primer mundo, pero dado que no existían en el país los mismos productos que en los países desarrollados, ese consumo estaba directamente dirigido, casi en forma suicida, a productos de importación. El trabajador, que por su salario alcanzaba estos lugares se sentía cercano a los sectores sociales de mayores recursos. Sin embargo, lo acotado en el tiempo que suelen ser los proyectos anclados en el mercado financiero hicieron que esa ilusión de ascenso social se desvaneciera prontamente $\underline{13}$.

Esta última situación y la posibilidad de construcción de identidades funcionales a los intereses del capital fue parte de un proceso que empieza en nuestro país con la dictadura militar de los setenta. A través de la represión, la apelación a la muerte como recursos disciplinarios, y el miedo consecuente, fueron desmembrándose la gran mayoría de los lazos colectivos que unían a los distintos colectivos sociales (tanto en su interior como entre los diversos grupos). Se generó un sustrato social y cultural dominado por la individualización feroz de la población. Se produjo una retracción de la población al interior de sus hogares, a lo privado, y se inculcó en ellos la idea de la existencia de un "enemigo" omnipresente. De esta forma, sembrando miedo de unos hacia otros, se destruía la posibilidad de encontrar un "nosotros" refractario, limitando o cercenando los canales de comunicación entre posibles "iguales" o "parecidos". Si se generan 
intersecciones en las relaciones de comunicación se pierde la posibilidad de que estos encuentren caminos comunes para la acción. Tal como afirma H. Arendt (1998), a través de "la acción y el discurso, los hombres muestran quienes son, revelan activamente su única y personal identidad y hacen su aparición en el mundo humano, mientras que su identidad física se presenta bajo la forma única del cuerpo y el sonido de la voz, sin necesidad de ninguna actividad propia". Si consideramos, junto con Arendt, que esta acción es fundamentalmente política, podemos observar que lo que se estaba mutilando, en definitiva, es la aparición de ese hombre en el espacio político y desde allí la posibilidad de encontrar un lugar de pertenencia común.

\section{La individualización forzada. Desde la dictadura militar hacia el menemismo}

La dictadura cumplió el papel de constructor de un espacio sociocultural que luego fue aprovechado y reforzado por la implantación del modelo neoliberal a través del menemismo. Se instaló en el seno de la sociedad argentina una nueva cultura, para lo cual era necesario destruir los cimientos sobre los cuales se había desarrollado la anterior $\underline{14}$. Entonces, el sindicalismo y el peronismo tradicional fueron los primeros blancos de los ataques, tanto materiales (represión) como discursivos (desprestigio permanente a través de los intelectuales orgánicos y los medios de comunicación ligados a las clases dominantes).

El espacio atacado en forma posterior, con el objetivo de sembrar un terreno fértil a la necesidad de un nuevo trabajador disciplinado, fue la educación pública, en todos sus niveles. El desfinanciamiento estatal y el empobrecimiento de los sectores que dependían de ella para su formación fueron elementos que contribuyeron al fraccionamiento de la población. Las clases medias fueron desplazando a sus hijos de los establecimientos educativos públicos para trasladarlos a los privados (tanto en el nivel primario como en el secundario). A su vez, se establecieron distintas gamas de colegios privados, que se distinguieron según el costo de los mismos, con lo cual también se producía una diferenciación al interior de la misma clase media, entre los menos pudientes y los mas acomodados. Otro tanto sucedió en el nivel universitario, donde los sectores de mayor poder adquisitivo hicieron una opción por la educación de sus hijos en universidades privadas, las cuales salieron a captar el mercado con una feroz campaña de marketing y la multiplicación de ofertas de carreras y posibles futuros laborales. En este caso, tal como sucedió en los dos anteriores, el discurso y la materialización de las prácticas neoliberales parecieron conjugar una dupla nefasta. Mientras se montaba una campaña de desprestigio para todo lo que tuviera al Estado o estuviera relacionado con "Io público", se liquidaba (presupuestariamente) a las estructuras que de ello dependían, entonces, finalmente, el 
discurso y la realidad parecían la misma cosa. Por otra parte, la educación "privatizada" o descentralizada fue el coto de casa de los intelectuales de derecha $\underline{15}$, que pasaron a utilizar ese medio como el más eficiente para la reproducción de sus cuadros y la difusión ideológica de su cultura. Este otro lugar (el de la educación pública) que se había ganado también se pierde, desde allí ya no se pueden pensar proyecciones o caminos certeros que conduzcan a futuros de bienestar. El futuro pasa a ser mucho mas incierto para los que acceden a la posibilidad de estudiar y aún, cuando se reciben, no es segura la inserción en espacios que les permitan ser uno de los ganadores.

El menemismo reforzó esta cultura a través de la lógica del éxito rápido, el consumo importado y la flexibilización de todas las conductas personales. La lógica de la intermitencia se transmitía desde el empleo a todas las relaciones sociales. Todo pasó a ser consumido y descartado como lo imponían las necesidades del "mercado". El problema fundamental de una sociedad estructurada de esa forma es que en ese mismo movimiento de consumo se estaba consumiendo a si misma.

Se reforzó la aculturización de una clase media absolutamente individualizada desde la dictadura militar, imponiendo valores asentados en la competencia despiadada por alcanzar el progreso individual. Lo paradójico de esta situación es que en muchos casos se trataba de hijos o nietos de obreros que rechazaban los valores pertenecientes a esa cultura y que, muy por el contrario, alentaban desde sus posicionamientos políticos, transformaciones institucionales que terminaban por minar las bases de sustento material de quienes ocupaban el lugar del trabajo asalariado. En cierta forma podemos decir que, con ingratitud, dejaban en el olvido el pasado que les había permitido llegar a la posición social que detentaban. De cualquier modo, relativizando esta última afirmación creemos que la causa fundamental de esta actitud es la existencia del corte generacional y cultural desarrollado por la dictadura militar, limando las referencias a valores que se habían comenzado a encarnar en la población, sobre todo en los más jóvenes.

Como expresamos mas arriba, el modelo de consumo que se impuso fue funcional a estos nuevos valores. Se asentó en la posibilidad de acceder a productos importados, de alta calidad y en cantidades crecientes día a día. Este mismo modelo fue potenciado por las publicidades de los medios masivos de comunicación, en las cuales se hace apelación a un consumidor joven, exitoso, de gran poder adquisitivo, que puede viajar y acceder a bienes de alto valor económico $\underline{16}$.

Se dispusieron todos los instrumentos para destruir la única barrera de defensa del modelo anterior que quedaba. Entonces, fueron las estructuras de protección estatales las 
que pasaron a ser desmembradas.

La batería de medidas tomadas por el gobierno, para desregular las normas relacionadas con el contrato de trabajo y la seguridad social, impactaron profundamente en el mercado de trabajo dislocando fundamentalmente todas las fuentes de empleo para los trabajadores. Así fue creciendo la desocupación y generando una situación de expansión continua de la pobreza. Esto hizo que los colectivos de trabajadores se volvieran cada vez mas fragmentados. El resultado lo vivimos actualmente cuando observamos que en un mismo espacio conviven hoy los trabajadores relativamente estables $\underline{17}$, los precarizados y los desocupados. Si antes el ámbito de la fábrica era el lugar preponderante para la unión y paso a la acción de la clase trabajadora, hoy ese ya no puede ser el "campo" (en el sentido de Bourdieu) para aglutinar las conciencias e iniciar acciones comunes. Si el mensaje ideológico esencial de la sociedad salarial era: "no importa el trabajo con tal que el pago llegue a fin de mes", hoy fue reemplazado por "no importa el monto del pago, lo importante es tener un empleo" (Gorz, 1997). El empleo asalariado, dejó de ser un atractor con potencia para incluir y distribuir ingresos para llegar a ser solo una ilusión vacía. Se llega a él bajo cualquier condición, incluso dejando de lado posibles resistencias y abandonando identidades propias.

\section{Colaboradores, clientes, asociados y precarios: las identidades del empleo "moderno"}

La amenaza permanente del desempleo hace que los de adentro no se sientan nunca dueños del lugar que ocupan, otros ven como sus dás pasan en la intermitencia de empleos temporarios y largos períodos de búsqueda de inserción, los que están afuera definitivamente se las arreglan para encontrar formas de trabajo absolutamente informales o vivir de la asistencia social. Pero todos comparten una misma sensación de angustia, eso resignifica el espacio del trabajo como común. Si bien, por un lado esta angustia es utilizada por el capital para disciplinar distinguiendo quienes entran de quienes se quedan afuera, otra vez pueden encontrarse igualdades por el trabajo: por lo menos se trata de una situación donde la ausencia real o virtual del empleo es lo que iguala. De cualquier modo, para todos el empleo asalariado dejó de ser sinónimo de lugar de proyección y seguridad. Por el contrario, es visto permanentemente como lo que puede desaparecer. Su obtención, se convirtió en una esperanza vana que carga las representaciones simbólicas del pasado y la inmediatez del presente.

Esta situación fue eliminando, poco a poco, la figura del obrero del imaginario de la población. Si hasta los setenta, este era el sujeto que podía llevar al país a la 
transformación, en las dos últimas décadas del siglo XX esa posición social pasó a ser parte de la historia. Para muchos trabajadores el "ser obrero" pasó a ser lo que "eran", cuando estaban en actividad, es el caso de los mas viejos o de los desocupados, en su referencia al momento en que tenían un empleo fijo. Para otros, los más jóvenes, ni siquiera ese valor está en su imaginario $\underline{18}$. Para algunos de estos últimos, sobre todo en los mas estables, sus referencias de "sí" están impregnadas por valores propios de la empresa, que incluso llegan a marcar su propia denominación como trabajadores (colaborador, asociado, cliente interno). Cuando se es obrero, "se obra", desde allí la producción es un elemento que, por este actuar, pasa a incorporar alguna forma de lo propio y desde allí permite resignificar el lugar ocupado en la fábrica desde un espacio distinto y distintivo. Cuando se es colaborador, el papel ocupado es absolutamente secundario, ya que sólo se colabora con otro que tiene el saber y controla todos los espacios del trabajo. El asociado es discursivamente puesto junto al capital, colocándolo como en una "caverna" platónica reproductora continua de elementos de dominación. Cuando, se le da el mote de "cliente" se lo identifica con "otro" totalmente extraño, que está fuera de la producción, que consume lo que el trabajador fabrica y cuya relación es directa con el capital. En este último sentido podemos decir que esta identificación no deja de ser perversa (esto no significa que las anteriores no lo sean), ya que con esta última denominación se trata de responsabilizar a los trabajadores en una relación (en la mayor parte de los casos virtual) ajena, que solo le compete al empresario. Es decir, el cliente es "un otro" totalmente novedoso para gran cantidad de trabajadores, con quien hasta este momento no se había enfrentado, pero ahora no solo lo enfrenta sino que debe adoptar su "forma", lo tiene incorporado a su misma figura y lo incomoda en su posición primigenia, donde debe ser lo que realmente es, una pieza contraria al capital en la relación característica del capitalismo. “Cada asalariado se debe considerar como proveedor de uno o varios clientes y cliente de uno o varios proveedores. Esta relación cliente-proveedor está en el centro de los dispositivos de calidad total. Ella es tambi én la justificación de las reorganizaciones de la gestión de producción y, mas allá, de la empresa en su conjunto. Ya no se trata de producir sin tener en cuenta la demanda y de intentar vender luego lo que se ha producido. Por el contrario se trata de responde a as demandas del mercado, de poner al cliente final en el centro de las actividades, de reaccionar permanentemente ante las evoluciones de sus deseos, de anticipar sus comportamientos de compra y de intentar responderlos exitosamente" (Dubar, 2000).

Por su parte, en el caso de los trabajadores precarizados podemos hablar de trabajos que dificultan las transacciones identitarias. La, incertidumbre inherente a la misma relación, la fuerte degradación respecto a los antecedentes de formación o de trabajo anteriores, un ingreso que suele ser absolutamente indigno y las condiciones de 
degradación para la realización habitual de tareas hacen que se vuelvan irreales las posibilidades de que los trabajadores incorporen parte de los valores allí generados a su propia identidad. Podemos decir entonces, que en muchos casos podría tratarse de la constitución de una identidad negativa, en la cual lo que prima es la memoria de "lo que se era", la angustia de no poder poner en práctica los saberes que de ella derivan y el rechazo a la situación actual.

Ser trabajador representa algo en el pasado (propio o familiar) pero muy poco de la situación presente o futura. En la realidad actual, de estos trabajadores, entonces se presentan dos opciones: trocar las identidades construidas en la socialización que antes otorgaba el trabajo por fragmentos de identidad débil, coyuntural y con el estigma del fracaso; o vivir como una transición un trabajo vacío de representaciones simbólicas, que solo aporta la estigmatización de la pobreza.

Resulta entonces grave que, por su escasa transmisión generacional y las fracturas que generaron la implementación de prácticas políticas y económicas neoliberales, la referencia a la cultura obrera quede diluida en el tiempo. Pero no resulta menos gravoso que, con ese mismo movimiento, haya quedado trunca la "promesa" de ascenso social que estaba inscrita en esos valores.

\section{EI lugar incierto y la identidad difusa}

De una situación donde el empleo asalariado, la relación política y/o sindical y la proximidad en el espacio social y cultural generaban identidades fuertes, individual y colectivamente, hoy nos encontramos con una realidad signada por la fragmentación e identidades vacías o móviles referidas al trabajo y, como consecuencia, por la enorme dificultad de construcción de identidades colectivas en los sectores populares.

En una sociedad donde el desempleo y la precarización son la norma, quienes cuentan con un empleo son mas propensos a la aceptación sin demasiadas resistencias de las restricciones impuestas en el ámbito de acción del capital. Quienes no tienen la posibilidad de tener un empleo, viven coaccionados por la insatisfacción de las necesidades vitales y a la espera de formas de salvación, que coyunturalmente toman la forma de asistencia estatal, o con la esperanza de obtener trabajos circunstanciales, en los cuales no pueden poner demasiadas expectativas de futuro. Bajo estas condiciones, el capital refuerza su posición de poder respecto del trabajo mediante mecanismos contractuales y organizacionales absolutamente disciplinadores. 
Hasta mediados de los setenta, desde el espacio político, el trabajador hacía suyo el espacio del trabajo en la fábrica. En la actualidad al haberse desdibujado el espacio de lo político el lugar de la fábrica pierde efectividad para asegurar la identidad del trabajador. El capital afirma su total poder sobre este espacio y lo utiliza para asegurar la acumulación sin demasiadas resistencias, mediante el disciplinamiento sistemático.

En el momento en el cual los trabajadores pierden la posibilidad de contar con un grupo de pertenencia exterior a la empresa, en ella no se generan circuitos que permitan dar significación a identidades comunes. En su interior las identidades pueden ser tan fragmentadas como en el exterior.

Hasta los setenta, a pesar de la convivencia de distintas formas ideológicas, la doctrina y el simbolismo peronista lograban concentrar en su seno una cultura del trabajo, la cultura del "ser obrero", acuñada desde sus orígenes. Desde mediados de los ochenta, y mas aún a partir del menemismo, la propiedad de dichos símbolos pasó a ser severamente cuestionada. La emergencia del neoliberalismo constituyó el punto de inflexión en la posibilidad de que bajo el mismo paraguas puedan convivir visiones tan diferentes de la realidad. Sobre todo, en los sectores de trabajadores mas jóvenes, el desarrollo del gobierno de Menem y la cercanía de algunos dirigentes sindicales al poder fue minando la posibilidad de su inserción bajo esa ideología. De cualquier modo, podemos argumentar también que la misma característica estructural e ideológica del peronismo, asentada en la convivencia de sectores sociales disímiles y patrones filosóficos variables en el tiempo fue el caldo de cultivo para la fragmentación que estalla con el menemismo.

El peronismo significó apropiación: de la plaza (de Mayo), de la política, de los símbolos (la marcha, las imágenes de Perón y Evita), desde el partido se otorgaba valor a los espacios y se los hacía propios. Así como con la fuerza de la marcha común se podía ocupar la plaza, los trabajadores tenían la convicción que la fábrica también podía ser ocupada. Cuando la plaza empezó a estar vacía como producto de un liderazgo político que transformaba al partido en algo ajeno $\underline{19}$, el poder de los trabajadores en la fábrica fue desvaneciéndose para dar paso al dominio casi absoluto del capital.

Cuando, enmascaradas bajo la figura del peronismo se implantaron las mas crudas medidas neoliberales, cuando se producía una identificación entre el discurso gubernamental y el de los principales sectores dominantes, y en el mismo momento en que los trabajadores pasaron a vivir uno de los momentos de mayor empobrecimiento de la historia de nuestro país, comenzó a diluirse la idea de "la vuelta". El regreso al poder de la clase trabajadora como tal, encarnado por el peronismo, se hizo cada vez mas lejano y 
difuso. En todo caso, el partido podía estar en el poder, pero comenzaba a apreciarse que ya no era en representación de los trabajadores.

Además, el lugar alcanzado por los obreros desde la sustitución de importaciones, a través del consumo, les había permitido ocupar un lugar dentro de los sectores medios. Ese nivel en la escala social constituía otra verdadera apropiación de un espacio social, desde donde se proyectaba un futuro de expansión y progreso. El neoliberalismo puso en cuestión todas las aristas de ese espacio y dejó endebles las esperanzas de ascenso social e inclusive de la misma permanencia entre las clases medias.

Uno de los mayores ejemplos de esta pérdida de lugar de los sectores medios lo representó la imposibilidad actual de validar la educación como una real fuente de progreso. La base social que ella permitía también fue puesta en cuestión por el neoliberalismo. Las estructuras educativas que servían de sustento a los sectores populares ya no cuentan con la misma potencia. El debilitamiento de la educación pública, que describimos mas arriba, y prácticamente la privatización de la misma, en sus niveles de mayor eficacia, hizo que estos ya no estén al alcance de quienes solo viven de un salario como obreros. Estos quedaron relegados a la educación pública mas deteriorada, con lo cual la valides de los títulos obtenidos está cada vez mas puesta en cuestión. Por otra parte, a medida que aumenta el número de desocupados y se desarrollan tecnologías mas complejas en la producción el grado de selectividad de las empresas hace que se desmerezcan los títulos obtenidos, debido a que los trabajadores con nivel secundario de formación pasan a ocupar el lugar que antes tenían los obreros y, aún los que tienen títulos universitarios el que tenían los técnicos. De esta forma para quienes no cuentan con estos grados de formación las alternativas se juegan entre dos opciones: la precarización o el desempleo.

Cuando todos estos espacios terminan siendo endebles quienes los ocupan pierden referencias estables y pasan a estar en una incertidumbre permanente. En este caso, poco puede hablarse de la posibilidad de constituir una cultura del trabajo como la que posiblemente había comenzado a construir el peronismo a través de la amalgama ideológica y política de la clase obrera. Al primar la incertidumbre en el lugar de trabajo, al estar asentados permanentemente en un terreno del cual no pueden apropiarse, ni siquiera mediante la afirmación del saber hacer, la identidad que a partir de dicho lugar se puede construir pasa a ser totalmente difusa y ambigua. El “campo", caracterizado por Bourdieu como espacio de lucha entre actores sociales, se constituye, a partir de la fragmentación de los trabajadores y la imposición de valores por parte de los empresarios, en un ámbito que asemeja un "escenario teatral", en el cual los individuos (que trabajan) 
representan papeles diferentes (producto de la polivalencia, el paso continuo entre distintos puestos precarios, entre otros.) muy mal retribuidos, y a partir de los cuales solo pueden mantener viva la esperanza de recuperar algún día un rol en el cual su propio papel adquiera mas relevancia que el maquillaje y el vestuario puesto por otros.

\section{Conclusión}

Si bien no podemos ya discutir la existencia o no del trabajo como fuente de realización material del hombre, si podemos afirmar que en su forma de empleo asalariado hoy ya no constituye el homogeneizador por antonomasia de las relaciones entre capital y trabajo.

La estructura social actual de nuestro país muestra en forma espectral la poliformidad del trabajo y del empleo. Entre los que quedan fuera de la fábrica están: los viejos obreros, los que momentáneamente se acercaron o acercan a esa condición, sin serlo totalmente porque ya esa cultura estaba en vías de extinción, y los que buscan acercarse infructuosamente a alguna forma de trabajo pero sin alcanzar éxito alguno. Aún entre ellos, las estrategias de trabajo los diferencian según el mayor o menor grado de informalidad de sus actividades (vendedores ambulantes, feriantes, cartoneros, entre otros). Su identidad sólo alcanza un grado de homogeneidad y certeza cuando desde lo político resignifican la estigmatización mediática del desocupado, pero vuelve a romperse en múltiples fracciones cuando tratan de colocarse como grupo frente a otros actores (el Estado, los partidos políticos, los sindicatos, entre otros) $\underline{20}$.

En la fábrica, ya no está el obrero, en el cual se encarnaron las promesas del progreso social y político de los sesenta y setenta. Otro trabajador lo ha reemplazado, mas joven, con mayores credenciales de formación general y más disciplinado individualmente a las necesidades del capital. Sin embargo, si consideramos que la relación capitalista no puede mensurarse solo a partir de aquello que sucede en las empresas mas grandes y modernas $\underline{21}$, sino en todo el espectro de la producción, vemos que este trabajador no es el único protagonista de la relación con el capital. Entonces lo que aparece en el mundo del trabajo asalariado es la convivencia de diversas identidades, la fragmentación también abarca este espacio, entre los mas jóvenes, mas apegados a culturas individualistas y desligados de toda posibilidad del establecimiento de lazos políticos, los mas viejos, que pueden arrastrar aún culturas cercanas al sindicalismo, y los precarizados cuyas identidades se hacen mas etéreas $y$, precisamente por la intermitencia natural de sus inserciones en la producción, sus posibilidades de acercamientos a expresiones sindicales o políticas resultan mas dificultosas. 
Si alguna vez lo hubo o, mejor dicho, si alguna vez tuvo posibilidades de constituirse en hegemónico entre los trabajadores, el particularismo obrero fue diluyéndose paulatinamente en Argentina, hasta hoy casi desaparecer.

Vivimos tiempos de identidades débiles y móviles en el trabajo, producto de las incertidumbres permanentes. Cuando tenemos un espacio fijo donde pararnos, desde él podemos mirar el horizonte y proyectarnos hacia otros lugares, podemos pensar caminos y distancias hacia donde nos podemos dirigir en el futuro. Eso representaban las identidades fuertes de los sesenta o setenta. Pero, en la actualidad, los lugares ya no están fijos por lo cual ya no podemos proyectarnos hacia otros lugares diferentes o más beneficiosos. Estamos permanentemente ocupando lugares distintos en diferentes momentos y entre períodos cada vez más cortos, lo cual hace que no tengamos un punto fijo desde donde colocarnos para ver hacia delante. Si los lugares son diversos, las direcciones cambian y los sentidos se entrecruzan, siempre hacia lugares que se hacen cada vez más virtuales.

Si en los años setenta el futuro de la clase obrera era el paraíso, el pecado de no haber concretado el sujeto que todos esperaban parece haberla conducido directamente al infierno.

Queda entonces por pensar si, ante la actual realidad, para los trabajadores argentinos el dolor de ya no ser es mas fuerte que la vergüenza de haber sido.

\section{Notas}

1. Para este artículo tomamos como parámetros principales de análisis a los trabajadores asalariados actuales (estables o precarizados), por considerar mas ajustada la posibilidad de efectuar una relación con la clase obrera preponderante en nuestro país entre los años cuarenta y mediados de los setenta.

2. R. Castel (1995) denomina como propiedad social a una suerte de término medio que incluye la protección social, la vivienda social, los servicios públicos, un conjunto de bienes colectivos provistos por la sociedad y puestos a disposición de los no propietarios para asegurarles un mínimo de recursos, permitirles escapar a la miseria, a la dependencia y a la decadencia social.

3. Según R. Castel (1995) la inclusión de las vacaciones en la legislación significó la inscripción “en la ley la posibilidad de no hacer nada que se estuviera obligado a hacer durante unos días al año, era reconocerle al trabajador el derecho a existir sencillamente, igual que los rentistas, los burgueses, los aristócratas, todos aquellos que en el imaginario obrero disfrutaban de la vida por la vida misma y para si mismos. Algunos días por año, la condición obrera 
coincidía con la condición burguesa".

4. Nos referimos al dinero que ingresa a los sindicatos por la cuota de cada uno de sus afiliados, y por las cláusulas obligacionales dirigidas a los trabajadores no afiliados y a los mismos empresarios.

5. La hotelería sindical, radicada en los distintos sectores turísticos pasó a ser una de las mas desarrolladas y confortables del país.

6. En este caso estamos haciendo referencia a los pobres urbanos que resultaban de migraciones internas en el país o quienes venían a Argentina huyendo de la guerra en Europa.

7. “Durante décadas el peronismo fue el lenguaje político que estructuró la experiencia subjetiva de los sectores populares". Desde 1945 y aún en los momentos de proscripción "el peronismo continuó siendo en los sectores populares una estructura activa que poseía la capacidad de organizar la experiencia cotidiana, a la vez política y privada". Canalizando a su vez "una dimensión obrerista y contracultural expresada entre otras cosas por la valoración del mundo del trabajo (sobre todo, del trabajador industrial), por el desprecio de los no-trabajadores, la nostalgia del esplendor populista y la proliferación de expresiones iconoclastas en el lenguaje popular". Referencia en el texto de Svampa (2000) a James D. Resistencia e integración, Sudamericana, Buenos Aires, 1990.

8. “(...) la política aparece como el principio articulador de las diferentes dimensiones subjetivas del trabajador metalúrgico, a partir de lo cual esta figura se dota de una identidad personal que se incorpora, a su vez, en una identidad colectiva mayor: sindicalistas que son más peronistas que trabajadores, pero también sujetos populares y peronistas en tanto obreros y sindicalistas". En este párrafo Svampa (2000) se está refiriendo al viejo militante sindical histórico.

9. La existencia del sindicato y la articulación del poder generado en los espacios laborales y locales a través de la CGT permitió al peronismo, en los momentos de proscripción del partido, continuar vigente y resignificar su legitimidad en los sectores populares. Una vez que el partido volvía al poder el sindicato dejaba de ser el único ámbito de pertenencia y relevaba parte de sus actividades con el partido.

10. Según C. Dubar (2000) la identidad se construye de manera problemática en la articulación entre un proceso relacional y un proceso biográfico. En esta construcción operan, por un lado, actos de atribución, vale decir definiciones socialmente legitimadas sobre lo que uno es (identidad para otro). Por el otro lado, actos de pertenencia que son definiciones subjetivas que expresan lo que uno quiere ser (identidad para ś). Entre estas dos dimensiones de la identidad puede haber desacuerdos. Esto da lugar a estrategias identitarias tendientes a reducir la brecha entre ellas, que pueden adoptar dos formas: a) Transacción externa u objetiva: entre el individuo y los otros significativos. Se tiende a acomodar la identidad para sí a la identidad para otro; b) Transacciones internas o subjetivas: entre la necesidad de salvaguardar una parte de sus identificaciones anteriores (heredadas) y el deseo de construirse nuevas 
identidades en el futuro (deseadas). Se tiende a asimilar la identidad para otro a la identidad para sí.

11. Decimos que la estabilidad es relativa porque ante la elevada tasa de desocupación y la precarización laboral que vivimos en Argentina no se puede decir que los trabajadores no vivan permanentemente la presión de ese afuera. Pero también debemos destacar que el modelo contractual argentino no garantiza la estabilidad a pesar de la existencia del contrato por tiempo indeterminado, ya que prevé la posibilidad del despido incausado.

12. Podemos decir que lo mismo ocurría en el fordismo, pero en él no se resquebarajaban las uniones entre los iguales que componían el espacio de trabajo.

13. Los movimientos financieros internacionales suelen determinar el emplazamiento de una determinada empresa en un país, en función del traslado a él de un proyecto productivo específico. Pero estos proyectos tienen la duración correspondiente a las necesidades generadas por los mismos mercados financieros y están a expensas de sus fluctuaciones. Una vez terminado el proyecto quienes lo conformaban, con contadas excepciones, pueden quedar sin empleo (Boltanski y Chiapello, 1999).

14. En el artículo "La democracia construida sobre la violencia", hago referencia a la transformación social y cultural que se generó en la Argentina con la dictadura militar y se reforzó en el menemismo a partir de la convertibilidad de la moneda y la consiguiente implantación del modelo neoliberal (Battistini, 2002).

15. No debemos descartar también que muchos intelectuales, bajo el paraguas del "progresismo", reciclaron sus ideas para encuadrar su actividad dentro de programas tecnocráticos de trabajo y líneas de investigación ligadas a los sectores dominantes. En muchos casos, se trataba de los mismos que en otras épocas trabajaban en directa relación con organizaciones de los sectores populares. En este sentido, podemos afirmar que el poder de chantaje y cooptación del capital fue otro de los elementos que contribuyó a la derrota ideológica que se puso de manifiesto durante toda la década de los noventa y los comienzos del nuevo siglo en Argentina.

16. Los medios masivos tienen el potencial, cada vez más efectivo (por la masividad y su referencia a la relación con la modernidad) de generar representaciones con gran valor simbólico, que en el caso de los jóvenes suelen tener mucha efectividad. Esto se refuerza por la ausencia de colectivos fuertes (sociales y políticos) que puedan generar valores contrapuestos.

17. No podemos hablar de total estabilidad en el empleo para estos trabajadores debido a que, aunque cuenten con contratos por tiempo indeterminado y ocupen puestos de gran importancia para la producción, la existencia de una oferta de trabajadores muy elevada, generada por la presión de una alta tasa de desempleo, hace que la seguridad no sea una de las características del empleo para ninguno de ellos.

18. Ellos no son verdaderamente "obreros" porque están obrerizados en superficie y casi siempre amenazados de 
caer en la asistencia. Solos y aislados frente a los "enemigos" dispersos (las agencias de empleo, los hogares, entre otros.), se agotan en combates individuales perdidos de entrada. Una de las características de su condición es el acortamiento de su horizonte, un encerramiento en la vida del día a día producido por el estatus de “no-persona social" (de "no-adulto" también): sin empleo estable y entonces sin vivienda, sin la posibilidad de estar presto al consumo, de donde se puede hablar de cierta forma de desocialización (Beaud y Pialoux, 1999).

19. “Lo que el vacío de la plaza atestigua en un nivel simbólico no es otra cosa que la transformación de la figura del conductor, la erosión de la eficacia simbólica de la noción de 'pueblo', verdadero lugar de pregnancia significativa de la vida política nacional durante cincuenta años. De ahora en más es necesario buscar el sentido de lo político en el testimonio de los 'ausentes "'. Frase final de La Plaza Vacía, trabajo en el cual Martuccelli y Svampa (1997) presentan la significación del peronismo a lo largo de la historia, sus relaciones con los sectores populares y la crisis de estas relaciones en los a ños noventa.

20. En este último caso nos estamos refiriendo a los grupos de desocupados, quienes logran dar contenido propio a la caracterización negativa que se les otorgaba, sobre todo desde los medios de comunicación, como "piqueteros", para constituirla en una forma de darse una identidad colectiva propia y enarbolarla como bandera de lucha frente al Estado. Cuando hablamos de su fragmentación nos referimos a la variedad de agrupaciones que representan a los grupos de desocupados en todo el país y a su expresión en diversas corrientes político-partidarias.

21. Sobre todo si consideramos que la tendencia de este tipo de empresas es la contratación de trabajadores de estas características.

\section{Referencias Bibliográficas}

1. Arendt, Hanna (1998), La condición humana, Ed. Paidós, Barcelona.

2. Battistini, Osvaldo (2002), “La democracia constituida sobre la violencia", en Battistini, O.: La atmósfera incandescente. Escritos políticos sobre la Argentina movilizada, Ed. Trabajo y Sociedad, Buenos Aires.

3. Beaud, S. y Pialoux, M. (1999), Retour Sur La Condition Ouvrière. Ed. Fayard, Paris.

4. Boltanski, L. y Chiapello, E. (1999), Le nouvel esprit du capitalisme, Ed. Gallimard, París.

5. Castel, Robert (1995), Las metamorfosis de la cuestión social. Una crónica del salariado, Ed. Paidós, Buenos Aires. 
6. Castel, R. y Haroche, C. (2001), “Propriété privée, propriété sociale, propriété de soi. Entretiens sur la construction de l'individu moderne, Ed. Fayard, Paris.

7. Dubar, Claude (2000), La socialisation, Ed. Armand Colin, Paris.

8. Gorz, André (1997), Miserees du présent. Richesse du possible, Ed. Galilée, Paris.

9. Martuccelli, D. y Svampa, M. (1997), La plaza vacía. Las transformaciones del peronismo, Ed. Losada. Buenos Aires.

10. Svampa, Maristella (2000), “I dentidades astilladas. De la patria metalúrgica al heavy metal", en Svampa, M.: Desde abajo. La transformación de las identidades sociales, Ed. Biblos, Buenos Aires. 